eligible for the randomised clinical trials (RCTs) performed leading up to registration of the respective pharmaceutical product.

Objectives: To determine whether patients with psoriatic arthritis who did not fulfil the inclusion criteria (group B) in RCTs receive similar benefits and drug survival from TNF inhibitors as those patients who would have fulfilled the inclusion criteria (group A).

Methods: All patients with rheumatic disorders who are treated with biologic DMARDs in Iceland are registered in ICEBIO. ICEBIO is based on the Danish Registry for biologic therapies in rheumatology ${ }^{2}$ and has data about approximately $98 \%$ of all patients with psoriatic arthritis treated with biologic DMARDs in Iceland. On February 1st 2016 there was information on 1058 individuals in ICEBIO.231 patients with psoriatic arthritis received their first-line treatment and could be classified according to inclusion criteria of respective pharmaceutical RCT. ${ }^{1}$ Information on disease activity at baseline was collected and we estimate the treatment response at 6 and 18 months according to ACR20 and DAS28CRP and drug survival.

Results: The groups were similar at baseline (table 1), although Group A predictably had higher SJC $(5,5$ vs 3,8$)$ and subsequently higher DAS28CRP (4.6 vs 4.2). Out of 231 patients we have sufficient data to determine ACR20 and DAS28CRP response in 92 and 91 patients respectively. Treatment response is outlined in table 2, with better response in group A in regards to HAQ and SJC. There was similar drug survival between the groups (figure 1).

\begin{tabular}{lccc}
\hline & Group & Group & p \\
& A & B & value \\
\hline VAS pain & $65 \pm 17$ & $64 \pm 22$ & 0.705 \\
VAS global & $71 \pm 21$ & $66 \pm 24$ & 0.222 \\
TJC & $6.3 \pm 3.8$ & $5.4 \pm 4.4$ & 0.198 \\
SJC & $5.5 \pm 3.3$ & $3.8 \pm 3.6$ & 0.003 \\
HAQ & $1.2 \pm 0.69$ & $1.0 \pm 0.65$ & 0.114 \\
DAS28CRP & $4.6 \pm 0.8$ & $4.2 \pm 0.9$ & 0.012 \\
\hline
\end{tabular}

Abstract THU0283 - Table 1. Group characteristics, mean values \pm SD.

\begin{tabular}{lccc}
\hline $\begin{array}{l}\text { Improvement in clinical } \\
\text { parameters: }\end{array}$ & $\begin{array}{c}\text { Included in } \\
\text { RCTs }\end{array}$ & $\begin{array}{c}\text { Not included in } \\
\text { RCTs }\end{array}$ & $\begin{array}{c}\mathbf{p} \\
\text { value }\end{array}$ \\
\hline$H A Q$ at 6 months & $-0.8 \pm 0.7$ & $-0.3 \pm 0.6$ & 0.008 \\
HAQ at 18 months & $-0.6 \pm 0.7$ & $-0.3 \pm 0.6$ & 0.051 \\
SJC at 6 months & $-4.3 \pm 2.7$ & $-2.2 \pm 2.7$ & 0.001 \\
SJC at 18 months & $-4.4 \pm 3.4$ & $-2.2 \pm 3.6$ & 0.007 \\
TJC at 6 months & $-4.2 \pm 3.8$ & $-2.8 \pm 5.1$ & 0.163 \\
TJC at 18 months & $-4.0 \pm 4.9$ & $-3.9 \pm 4.1$ & 0.889 \\
ACR20 at 6 months & $77 \%$ & $60 \%$ & 0.207 \\
ACR20 at 18 months & $69 \%$ & $59 \%$ & 0.545 \\
DAS28CRP at 6 months & $77 \%$ & $71 \%$ & 0.749 \\
DAS28CRP at 18 months & $81 \%$ & $67 \%$ & 0.304 \\
\hline
\end{tabular}

Abstract THU0283 - Table 2. Response to first-line TNF $\alpha$ inhibitors, mean values and percentage achieving response by ACR20 or decrease in disease activity by DAS28CRP.

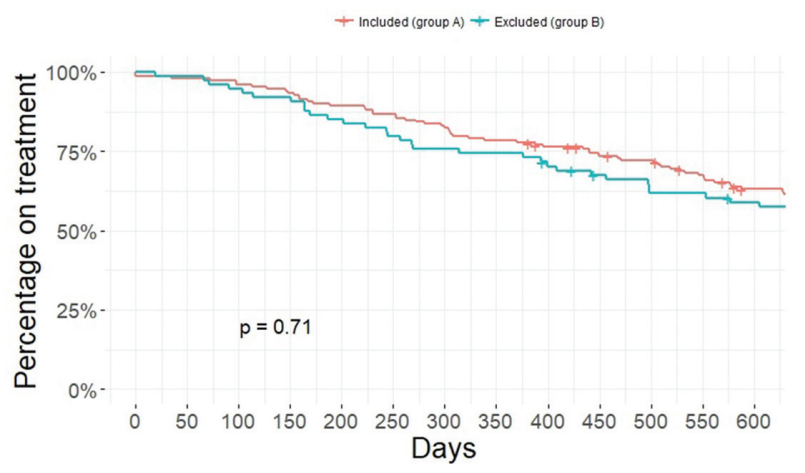

Abstract THU0283 - Figure 1. First-line TNF inhibitor drug survival

Conclusions: Patients with psoriatic arthritis that would not have fulfilled the inclusion criteria in RCTs seem to respond to treatment effectively and have similar drug survival. Thus, treatment outcomes for psoriatic arthritis from RCTs may probably be applied to daily clinical practice, whether patients would have fulfilled RCT criterias or not. However, more detailed studies are needed.
REFERENCES:

[1] Runarsdottir EE, Gunnarsdottir AI, Love TJ, Gunnarsson PS, Gudbjornsson $B$. The majority of patients with psoriatic arthritis are not eligible for randomized clinical trials.

[2] DANBIO 2017. https://danbio-online.dk/om-danbio.

Disclosure of Interest: None declared

DOI: 10.1136/annrheumdis-2018-eular.7457

\section{THU0284 \\ HAQ IN PSORIATIC ARTHRITIS IS DRIVEN BY GENDER, INFLAMMATION AND AGEING: OBSERVATIONAL DATA FROM COHORT STUDIES IN UK, DENMARK, ICELAND AND SWEDEN}

${ }^{1}$ L.E. Kristensen, T.S. Jørgensen ${ }^{1}$, L.C. Coates ${ }^{2}$, P. Frederiksen ${ }^{1}$, B. Gudbjornsson ${ }^{3}$, J.K. Wallman ${ }^{4}$, N. McHugh ${ }^{5}$, M.C. Kapetanovic ${ }^{6}$, L. Dreyer ${ }^{7}$, W. Tillett ${ }^{5}{ }^{1}$ The Parker Institute, Copenhagen University Hospital, Bispebjerg and Frederiksberg, Copenhagen F, Denmark; ${ }^{2}$ Leeds Institute of Rheumatic and Musculoskeletal Medicine, University of Leeds, Leeds, UK; ${ }^{3}$ Centre for Rheumatology Research, University Hospital and Faculty of Medicine, University of Iceland, Reykjavik, Iceland; ${ }^{4}$ Department of Clinical Sciences Lund, Rheumatology, Lund University, Lund, Sweden; ${ }^{5}$ Royal National Hospital for Rheumatic Diseases, Bath, UK; ${ }^{6}$ Department of Clinical Sciences, Lund, Section of Rheumatology Lund University and Skåne University Hospital, Lund, Sweden; ${ }^{7}$ Center for Rheumatology and Spine diseases, Rigshospitalet Gentofte,, Hellerup, Denmark

Background: Psoriatic arthritis (PsA) is a chronic inflammatory disorder associated with skin and joint involvement, pain and impaired function. HAQ has been widely used but components contributing to $\mathrm{HAQ}$ and changes thereof have been sparsely studied.

Objectives: The objective of this multinational population-based cohort study was to investigate factors associated with longitudinal changes in HAQ in patients with PsA in independent settings.

Methods: Data on PsA patient characteristics, disease activity components and HAQ was obtained from the DANBIO (Denmark), ICEBIO (Iceland), SSATG (southern Sweden) and BATH (UK) cohort registries. Farewell's linear increments model for missing data was used to fit each longitudinal response by regressing the observed increments onto lagged values of the response variables $(\mathrm{HAQ}$, CRP and VAS pain) while also adjusting for other covariates (gender, age and disease duration). Due to homogeneity of the nature of registries, the Nordic data was pooled for patients initiating first course of biologics (anti-TNF therapy, secukinumab or ustekinumab), whereas UK data represents an ongoing cohort with different treatments.

Results: In the period 2006 through 2016, we identified 1473 patients from DANBIO, 168 from ICEBIO, 469 from BATH, and 716 from SSATG eligible for analyses. Mean age in years (SD) and percentage of females for the populations were 46 (SD \pm 12 ), $55 \%$ for DANBIO, 46 (SD \pm 12 ), $61 \%$ for ICEBIO, 47 (SD \pm 11 ), $51 \%$ for SSATG, and 58 (SD \pm 13 ) $49 \%$ for BATH; respectively. The figure displays observed $\mathrm{HAQ}$ values (solid lines) and Farewell modelled (broken lines) curves divided on gender for the development of HAQ after initiation of biologic therapy for pooled Nordic data $(A)$ and for the ongoing UK cohort (B). It should be noted, that Farewell modelling inflates HAQ-values in the Nordic registries reflecting a correction for channelling bias due to drop out during biologic treatment. Whereas the modelled $\mathrm{HAQ}$ values for the BATH cohort are deflated possibly due to extra visits during flares in this ongoing observational cohort. At all time points and cohorts female HAQ values are higher than males $(p<0.001)$. After initiation of biologic therapy there is a significant decline in the HAQ scores in the Nordic registers of $0.23(95 \%$ $\mathrm{Cl} 0.21-0.25)$ at 6 months. Changes in CRP, VAS-pain nor disease duration did not appear to affect $\mathrm{HAQ}$ during follow-up. However, ageing seemed to have a tendency to increase HAQ over time. The same consistent pattern was present when analyses were done separated by country (data not shown). 

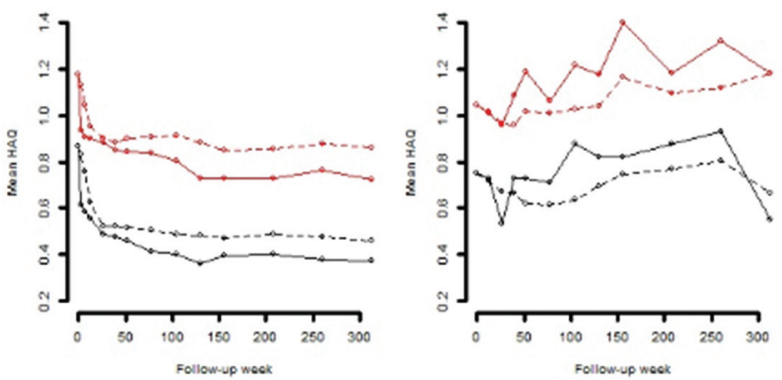

Conclusions: In PsA, across independent European cohorts, HAQ is higher for women, and significantly decreases for both genders when anti-inflammatory treatment is initiated. HAQ does not depend on CRP, VAS-pain or disease duration during longitudinal follow-up. However, a significant increasing trend was identified with ageing

Acknowledgements: This study was supported by unrestricted grants from The Oak foundation, and NordForsk.

Disclosure of Interest: L. E. Kristensen Speakers bureau: Pfizer, AbbVie, Amgen, UCB, Celgene, BMS, MSD, Novartis, Eli Lilly, Janssen Pharmaceuticals, T. S. Jørgensen Speakers bureau: Abbvie, Roche, UCB, Novartis, Pfizer, Biogen and Eli Lilly, L. Coates: None declared, P. Frederiksen: None declared, B. Gudbjornsson: None declared, J. Wallman Consultant for: AbbVie, Celgene, Eli Lilly, Novartis, UCB, N. McHugh Grant/research support from: Pfizer, Celgene and Abbvie, Speakers bureau: Eli Lily, Pfizer and Abbvie, M. Kapetanovic: None declared, L. Dreyer Speakers bureau: UCB, MSD, Janssen, W. Tillett Speakers bureau: Abbvie, Celgene, Eli Lilly, Janssen, Novartis, Pfizer, UCB

DOI: 10.1136/annrheumdis-2018-eular.2908

\section{THU0285 THE EFFECT OF FAMILY HISTORY ON DISEASE PHENOTYPES IN 1393 PSORIATIC ARTHRITIS PATIENTS}

D. Solmaz ${ }^{1}$, S.B. Ureyen ${ }^{1}$, G. Kimyon ${ }^{2}$, E.K. Gunal ${ }^{3}$, A. Dogru', O. Bayindir ${ }^{5}$ E. Dalkilic ${ }^{6}$, C. Ozisler ${ }^{7}$, M. Can ${ }^{3}$, S. Akar ${ }^{5}$, G.Y. Cetin ${ }^{8}$, S. Yavuz ${ }^{3}$, L. Kilic ${ }^{3}$, E. F. Tarhan ${ }^{5}$, O. Kucuksahin ${ }^{7}$, A. Omma ${ }^{7}$, E. Gonullu ${ }^{9}$, F. Yildiz ${ }^{10}$, E.D. Ersozlu ${ }^{11}$,

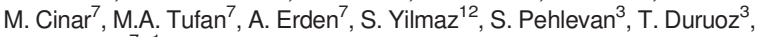
U. Kalyoncu', ${ }^{1}$ S.Z. Aydin, on behalf of PsArt-ID (Psoriatic Arthritis-International Database). ${ }^{1}$ PsArt-ID, Ottawa, Canada; ${ }^{2}$ PsArt-ID, Gaziantep; ${ }^{3}$ PsArt-ID, Istanbul; ${ }^{4}$ PsArt-ID, Isparta; ${ }^{5}$ PsArt-ID, Izmir, ${ }^{6}$ PsArt-ID, Bursa; ${ }^{7}$ PsArt-ID, Ankara; ${ }^{8}$ PsArt-ID, Kahramanmaras; ${ }^{9}$ PsArt-ID, Eskisehir, ${ }^{10}$ PsArt-ID, Van; ${ }^{11}$ PsArt-ID, Adana;

${ }^{12}$ PsArt-ID, Konya, Turkey

Background: Psoriatic arthritis (PsA) has a genetic background, approximately $40 \%$ of patients having a family history of psoriasis or PsA in first-degree relatives, which may impact the disease features.

Objectives: The aim of this study was to evaluate the effects of family history of psoriasis or PsA on the disease phenotypes.

Methods: The demographic and clinical data were retrieved from the longitudinal, multicenter PsArt-ID (Psoriatic Arthritis-International Database). Family history of psoriasis and PsA were investigated for 1 st and 2nd degree relatives separately. The effect of the family history of psoriasis and/or PsA on disease phenotypes and severity were analysed, calculating the relative risks (RR)

Results: 1393 patients had the data for family history, $444(31.9 \%)$ of whom was positive for psoriasis and/or PsA. The majority of the family history was only psoriasis $(333 / 444 ; 75 \%)$ and $58.5 \%$ (260/444) of the patients had first-degree relatives affected. There was no differences in maternal or parental transmission rates however women had more psoriasis and/or PsA in their family $67.3 \%$ vs $32.7 \%$ p: 0.028 ). Patients with a family history had an earlier onset of age for psoriasis $(29 \pm 14.8$ vs $31 \pm 14.9 \mathrm{p:}$ : 0.007$)$, more frequent nail involvement $(50.7 \%$ vs $29.6 \%$ p: 0.032 ), more frequent enthesitis ( $28.2 \%$ vs $17.7 \%$ p $<0.001)$ and deformities $(25.2 \%$ vs $19.9 \%$ p: 0.05$)$ and were able to achieve minimal disease activity (MDA) less often. (38.6\% vs $49.5 \%$ p: 0.045$)$. Plaque psoriasis was more common if the family history was positive for psoriasis whereas pustular psoriasis was more frequent when the family history was positive for PsA (figure 1). Family history of psoriasis were found as a risk factor for a younger onset (RR: 1.138), for nail disease (RR: 1.179), for enthesitis (RR: 1.504) and for not achieving MDA (RR: 1.246) whereas family history of PsA was a risk factor for having deformities (RR: 1.215) (table 1).
Abstract THU0285 - Table 1. Relative Risks in patients with or without family history of psoriasis or PsA

\begin{tabular}{lcccc}
\hline & $\begin{array}{c}\text { Family } \\
\text { history }\end{array}$ & $\mathrm{p}$ & $\mathrm{RR}$ & $95 \% \mathrm{Cl}$ \\
\hline $\begin{array}{l}\text { Onset of psoriasis before } 40 \text { years } \\
\text { age }\end{array}$ & Psoriasis & $<0.05$ & $\mathbf{1 . 1 3 8}$ & $\mathbf{1 . 0 6 3 -}$ \\
& & & & $\mathbf{1 . 2 1 9}$ \\
& PsA & $>0.05$ & 1.023 & $0.879-$ \\
Nail involvement (ever) & & & 1.191 \\
& Psoriasis & $<0.05$ & $\mathbf{1 . 1 7 9}$ & $\mathbf{1 . 0 4 - 1 . 3 3 5}$ \\
& PsA & $>0.05$ & 1.157 & $0.917-$ \\
Enhesitis (ever) & & & 1.461 \\
& Psoriasis & $<0.05$ & $\mathbf{1 . 5 0 4}$ & $\mathbf{1 . 1 9 2 -}$ \\
& & & $\mathbf{1 . 8 9 8}$ \\
Not achieving MDA & PsA & $>0.05$ & 1.350 & $0.871-$ \\
& & & 2.092 \\
& Psoriasis & $<0.05$ & $\mathbf{1 . 2 4 6}$ & $\mathbf{1 . 0 0 3 -}$ \\
& & & & $\mathbf{1 . 5 4 7}$ \\
Presence of deformities & PsA & $>0.05$ & 1.044 & $0.655-$ \\
& & & & 1.666 \\
& Psoriasis & $>0.05$ & 1.215 & $0.928-$ \\
& & & & 1.592 \\
& PsA & $<0.05$ & $\mathbf{1 . 7 8 6}$ & $\mathbf{1 . 1 7 0 -}$ \\
& & & & $\mathbf{2 . 7 2 7}$ \\
\hline
\end{tabular}

PsA: Psoriatic Arthritis; MDA: Minimal Disease Activity

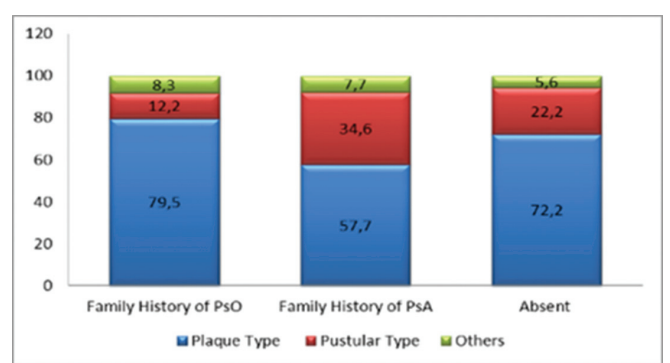

Figure: Distribution of skin lesions according to the family history in patients with PsA. Numbers are given as percentages. PsO: Psoriasis; PsA: Psoriatic Arthritis

Conclusions: The family history of psoriasis and PsA has impacts on skin phenotypes, musculoskeletal features and the disease severity. The differences between family history of psoriasis and PsA and pustular vs plaque phenotypes may point out to a different genetic background and pathogenic mechanisms in these subsets.

Disclosure of Interest: None declared

DOI: 10.1136/annrheumdis-2018-eular.2357

\section{THU0286 PREDICTORS FOR ORTHOPAEDIC SURGERY IN PATIENTS WITH PSORIATIC ARTHRITIS. RESULTS FROM A RETROSPECTIVE COHORT STUDY OF 590 PATIENTS DIAGNOSED 1954-2011, AND FOLLOWED UP UNTIL 2017}

${ }^{1,2}$ T.W. Nystad, Y. Husum ${ }^{1}$, O.N. Furnes ${ }^{2,3}$, B.T.S. Fevang ${ }^{1,2,4} .{ }^{1}$ Bergen group of Epidemiology and Biomarkers in Rheumatic Disease, Department of Rheumatology; ${ }^{2}$ The Norwegian Arthoplasty Register, Department of Orthopaedic surgery, Haukeland University Hospital; ${ }^{3}$ Department of Clinical Medicine;

${ }^{4}$ Department of Clinical Science, University of Bergen, Bergen, Norway

Background: Psoriatic arthritis with peripheral joint affection is a progressive dis ease in most patients, and erosions are seen in $47 \%$ within the first two years. Synthetic disease modifying anti rheumatic drugs (DMARDs) are generally prescribed, to inhibit inflammation, but have not been proven to slow or prevent radiographic changes. Biologic treatment is recommended when other agents are not efficient, and has been shown to give better control of structural damage. ${ }^{2}$

Orthopaedic corrective surgery has been a necessary part of treating patients with psoriatic arthritis, when medication fails to prevent joint destruction. Surgery can be considered a proxy for joint damage, and studying time trends in orthopaedic surgery thus gives valuable information regarding the prognosis of patients with inflammatory arthritis. In patients with rheumatoid arthritis there has, over time, been a declining incidence of orthopaedic interventions. The change in available medical treatment is believed to be responsible for this. ${ }^{3}$ As synthetic 